\title{
Erratum to: The Great Recession and the Changing Geography of Food Stamp Receipt
}

\author{
Tim Slack • Candice A. Myers
}

(C) Springer Science+Business Media Dordrecht 2014

Figure 2 has been published incorrectly in the original publication of the article. The correct version of the figure is provided below.

The online version of the original article can be found under doi:10.1007/s11113-013-9310-9.

T. Slack $(\bowtie)$

Louisiana State University, 126 Stubbs Hall, Baton Rouge, LA 70803, USA

e-mail: slack@1su.edu

C. A. Myers

Pennington Biomedical Research Center, 6400 Perkins Road, Baton Rouge, LA 70808, USA 


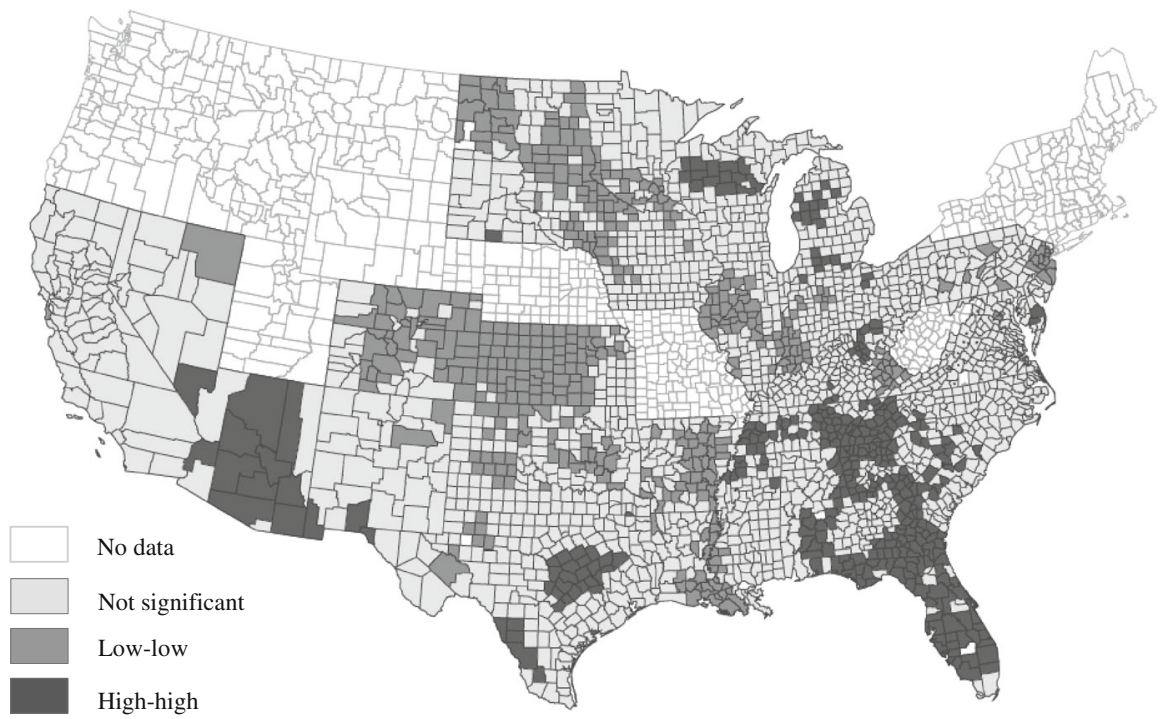

Fig. 2 LISA map of county-level change in SNAP receipt, 2007-2009. Source US Department of Agriculture. Notes Moran's $I=0.47$. 'Low-low' refers to counties at the center of geographic clusters with significantly lower change in SNAP receipt than would be expected at random. 'High-high' refers to counties at the center of geographic clusters with significantly higher change in SNAP receipt than would be expected at random 